\title{
Practical tetrafluoroethylene fragment installation through a coupling reaction of (1,1,2,2-tetrafluorobut-3-en-1-yl)zinc bromide with various electrophiles
}

\author{
Ken Tamamoto, Shigeyuki Yamada and Tsutomu Konno*
}

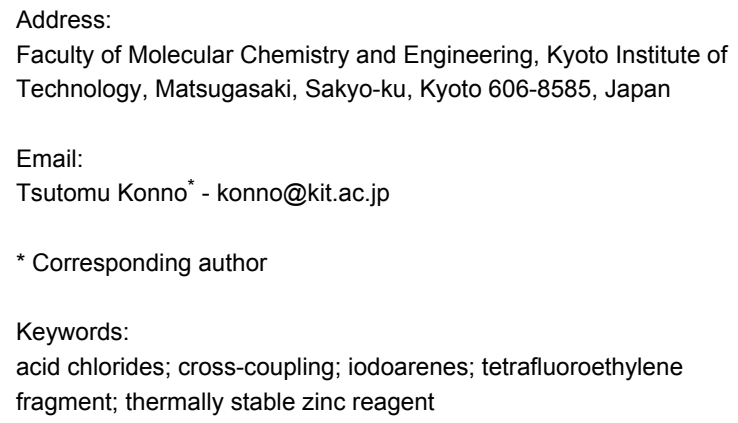

Beilstein J. Org. Chem. 2018, 14, 2375-2383.

doi:10.3762/bjoc. 14.213

Received: 15 May 2018

Accepted: 04 July 2018

Published: 11 September 2018

Associate Editor: L. Ackermann

(C) 2018 Tamamoto et al.; licensee Beilstein-Institut. License and terms: see end of document.

\begin{abstract}
(1,1,2,2-Tetrafluorobut-3-en-1-yl)zinc bromide was prepared by insertion of the zinc-silver couple into the $\mathrm{CF}_{2}-\mathrm{Br}$ bond of commercially available 4-bromo-3,3,4,4-tetrafluorobut-1-ene in DMF at $0{ }^{\circ} \mathrm{C}$ for $0.5 \mathrm{~h}$, The resultant polyfluorinated zinc reagent was found to be thermally stable at ambient temperature and storable for at least 1.5 years in the refrigerator. This $\mathrm{CF}_{2} \mathrm{CF}_{2}-\mathrm{Containing}$ organozinc reagent could be easily transmetallated to copper species, which underwent cross-coupling reactions with various aromatic iodides or acyl chlorides to produce a broad range of $\mathrm{CF}_{2} \mathrm{CF}_{2}$-containing organic molecules in good-to-excellent yields. Therefore, the zinc reagent could become a new and practical synthetic tool for producing functional molecules with a $\mathrm{CF}_{2} \mathrm{CF}_{2}$ fragment.
\end{abstract}

\section{Introduction}

Recently, much attention has been paid to organic compounds containing a perfluoroalkylene unit, e.g., $-\left(\mathrm{CF}_{2}\right)_{n}{ }^{-}$, in various fields, such as medicine and materials sciences [1-4], because incorporation of multiple fluorine atoms into organic substances causes dramatic alterations in the chemical and physical properties of substances, which may significantly enhance their potential functionality $[5,6]$. Notably, organofluorine compounds bearing a tetrafluoroethylene $\left(-\mathrm{CF}_{2} \mathrm{CF}_{2}-\right)$ unit have attracted significant interest as a promising framework for various functional molecules. In the medicinal field, for example, Linclau and co-workers reported the first enantioselective synthesis and the intriguing biological activities of $\mathrm{CF}_{2} \mathrm{CF}_{2}$-containing pyra- nose and furanose derivatives (Figure 1a) [7-9]. Subsequently, Gouverneur et al. also developed novel $\mathrm{CF}_{2} \mathrm{CF}_{2}$-containing C-nucleosides (Figure 1b) [10]. Meanwhile, in the field of materials sciences, Kirsch et al. revealed that the incorporation of the $\mathrm{CF}_{2} \mathrm{CF}_{2}$ unit between two cyclohexane rings caused significant enhancement in thermal stability in a liquid crystalline phase (Figure 1c) [11]. In addition to the development of a convenient access to $\mathrm{CF}_{2} \mathrm{CF}_{2}$-containing pyranoses [12], our group also showed that tricyclic mesogens with a $\mathrm{CF}_{2} \mathrm{CF}_{2}$-containing carbocycle exhibited large negative dielectric anisotropies (Figure 1d), which would be promising for candidates for vertically aligned (VA)-type display materials [13-17]. Owing to 


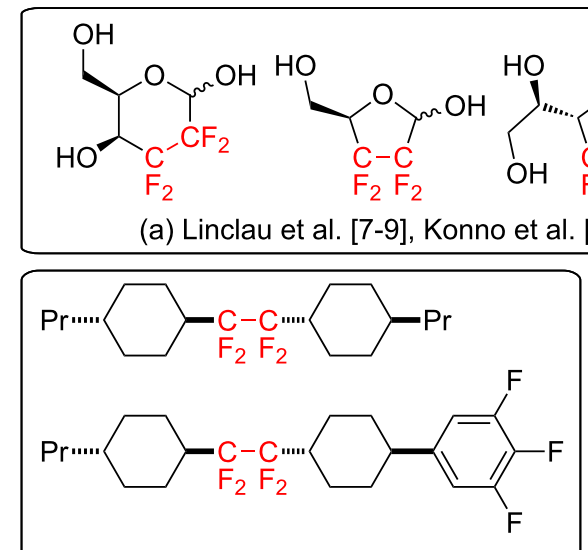

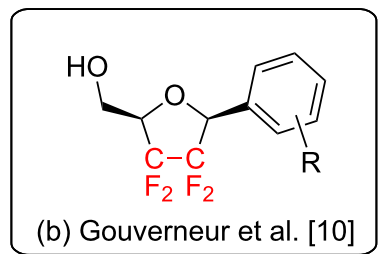

(b) Gouverneur et al. [10] (c) Kirsch et al. [11]

Figure 1: Functional molecules with $\mathrm{CF}_{2} \mathrm{CF}_{2}$-fragment.

such valuable applications, the development of a much more efficient synthetic protocol for $\mathrm{CF}_{2} \mathrm{CF}_{2}$-containing organic molecules has a high priority in various research areas.

A number of synthetic protocols for $\mathrm{CF}_{2} \mathrm{CF}_{2}$-containing molecules have been developed in the last half-decade. Ogoshi and co-workers reported an efficient synthetic protocol for $\mathrm{CF}_{2} \mathrm{CF}_{2}-$ containing compounds via carbocupration or oxycupration of tetrafluoroethylene (TFE) [18-20]. Gouverneur et al. disclosed a $\mathrm{Cu}(\mathrm{I})$-mediated cross-coupling reaction using $\mathrm{ArCF}_{2} \mathrm{CF}_{2} \mathrm{SiMe}_{3}$ derivatives that produced the corresponding tetrafluoroethylenated compounds [21]. Beier's group also described a broad range of tetrafluoroethylene compounds generated by the reductive coupling of in situ-formed $\mathrm{RCF}_{2} \mathrm{CF}_{2} \mathrm{MgCl} \cdot \mathrm{LiCl}$ with various electrophiles $[22,23]$. Our group revealed that commercially available 4-bromo-3,3,4,4-tetrafluorobut-1-ene (1) underwent a $\mathrm{Cu}(0)$-mediated cross-coupling reaction with aromatic iodides in DMSO at $160{ }^{\circ} \mathrm{C}$ in a sealed-tube apparatus [24] or reductive couplings with various carbonyl compounds [25], leading to good yields of versatile $\mathrm{CF}_{2} \mathrm{CF}_{2}$-containing substances. However, many obstacles to practical synthesis remain, e.g., the use of 1,2-dibromotetrafluoroethane (Halon2402) with ozone depletion and global warming potentials as a starting material [26], explosive and difficult-to-handle gaseous tetrafluoroethylene [18-20], thermally unstable polyfluoroalkylmetal species $[8,27,28]$, etc. Therefore, the development of a more efficient synthetic protocol featuring easy-handling, simple preparation, and thermal stability is highly desirable.

Our strategy focused on the preparation of a thermally stable $\mathrm{CF}_{2} \mathrm{CF}_{2}$-containing metal species for which the "unreactive" form can be easily changed to the "reactive" form through chemical transformation. Out of a variety of organometallics, we selected an organozinc reagent that possesses higher ther- mal stability than the corresponding organolithium or -magnesium species due to the almost covalent $\mathrm{C}-\mathrm{Zn}$ bond $[29,30]$. Moreover, organozinc reagents can be easily transformed to the "reactive" species, through a transmetallation process with a transition metal (e.g., $\mathrm{Pd}$ or $\mathrm{Cu}$ ), which can efficiently construct a new $\mathrm{C}-\mathrm{C}$ bond [30-32]. Thus, we aimed at the development of an efficient preparation of a thermally stable organozinc reagent, possessing a $\mathrm{CF}_{2} \mathrm{CF}_{2}$ fragment as a thermally stable tetrafluoroethylenating agent, and successive $\mathrm{C}-\mathrm{C}$ bond formation to produce a wide variety of $\mathrm{CF}_{2} \mathrm{CF}_{2}$-containing molecules, and the results are described in this article (Scheme 1).

\section{Results and Discussion}

We carried out the optimization of the reaction conditions for the preparation of $\mathbf{2 - Z n}$ by direct zinc insertion into the $\mathrm{CF}_{2}-\mathrm{Br}$ bond of commercially available fluorinated substance 1 . The results are summarized in Table 1.

Initially, we attempted zinc insertion using a typical protocol [33], i.e., treating 1 with 2.0 equiv of zinc powder, pre-activated with dilute $\mathrm{HCl}$ solution, in $\mathrm{DMF}$ at $0{ }^{\circ} \mathrm{C}$ for $0.5 \mathrm{~h}$. Unfortunately, no desired zinc insertion occurred and substrate $\mathbf{1}$ was quantitatively recovered (Table 1, entry 1). Interestingly, when a zinc-silver couple $\mathrm{Zn}(\mathrm{Ag})$ [34] was employed instead of zinc powder, the desired zinc insertion took place very smoothly to form the desired (1,1,2,2-tetrafluorobut-3-en-1-yl)zinc bromide $(\mathbf{2 - Z n )}$ in $86 \%$ NMR yield, along with a small amount of a reduction byproduct (2-H) (Table 1, entry 2). Reducing the amount of $\mathrm{Zn}(\mathrm{Ag})$ slightly retarded the zinc insertion, with only $50 \%$ NMR yield (Table 1, entry 3 ). Lowering the temperature to $-30{ }^{\circ} \mathrm{C}$ also inhibited the zinc insertion, with quantitative recovery of 1 (Table 1 , entry 4 ). The reaction was also attempted in various solvents, namely $N, N$-dimethylacetamide (DMA), $N, N$ '-dimethylpropyleneurea (DMPU), $N$-methylpyrro- 


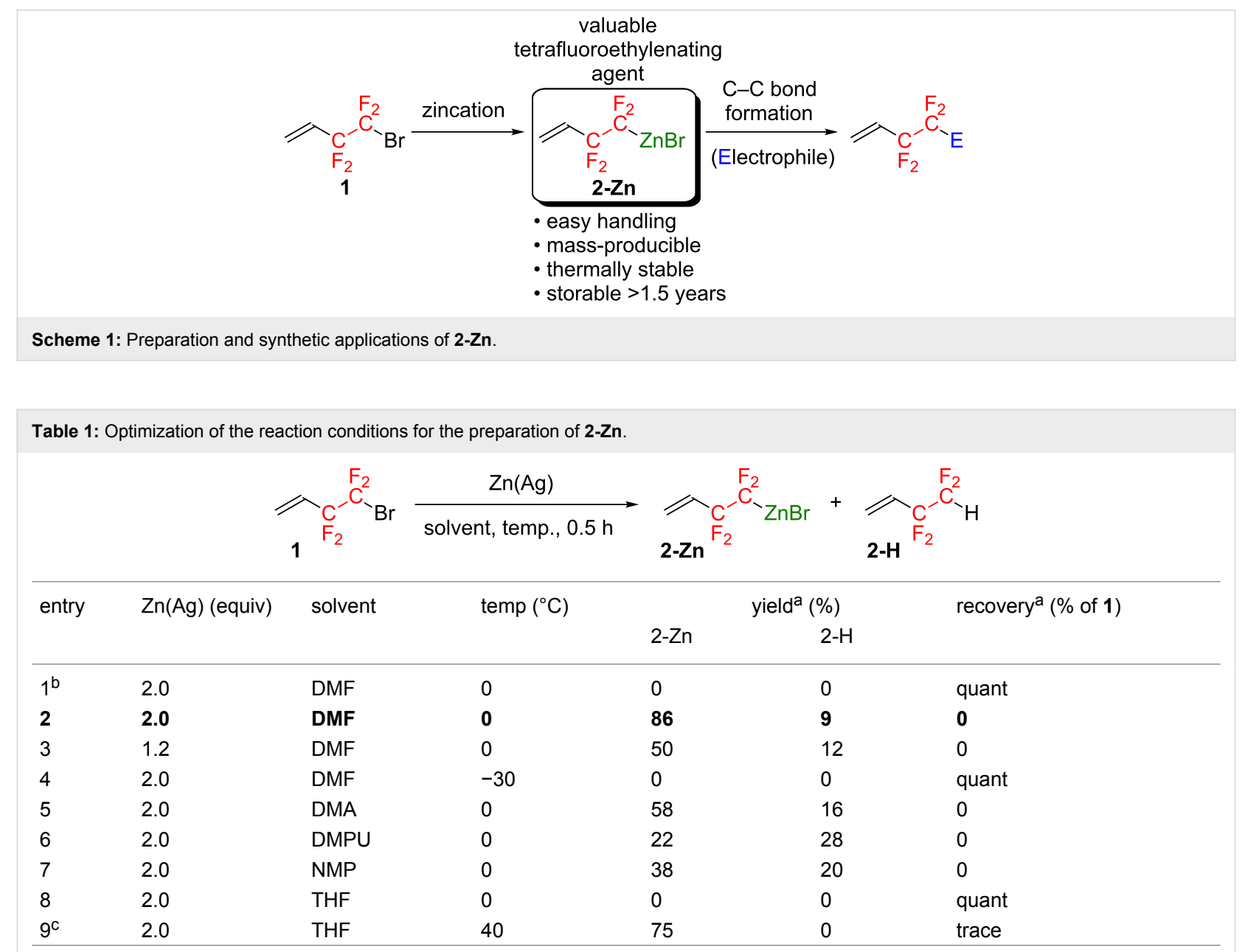

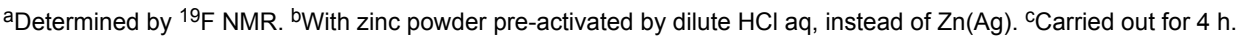

lidin-2-one (NMP), and THF. In polar solvents (DMA, DMPU, and NMP), the reaction successfully produced the desired $\mathbf{2 - Z n}$, although the yield was still unsatisfactory $(22-58 \%$, Table 1 , entries 5-7). In the less polar THF, in contrast, complete recovery of 1 was observed (Table 1, entry 8). Nevertheless, after raising the temperature to $40{ }^{\circ} \mathrm{C}$, directed zinc insertion into the $\mathrm{CF}_{2}-\mathrm{Br}$ bond was achieved in THF, producing $\mathbf{2 - Z n}$ in $75 \%$ NMR yield (Table 1, entry 9). Eventually, the optimal

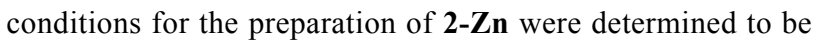
that given in entry 2 (Table 1 ). It is noteworthy that $\mathbf{2 - Z n}$ can be prepared in DMF or THF on a large scale (approx. 40-50 mmol scale) without any problem. More remarkably, the prepared 2-Zn can be stored in DMF solution (ca. $0.70 \mathrm{M}$ ) for at least 1.5 years in the refrigerator [35].

In order to examine the stability of $\mathbf{2 - Z \mathbf { n }}$ in more detail, we quantitatively evaluated the thermal stability of $\mathbf{2 - Z n}$ under various temperature conditions (Figure 2). After a given duration, the recovery yield of $\mathbf{2}-\mathbf{Z n}$ was determined by ${ }^{19} \mathrm{~F}$ NMR analysis using an internal reference.

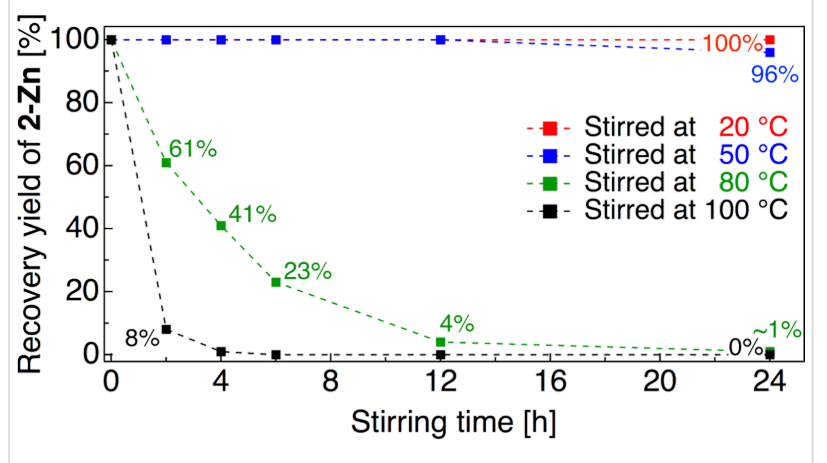

Figure 2: Recovery yield of 2-Zn in DMF (ca. $0.70 \mathrm{M}$ ) after stirring at various temperature conditions.

Complete recovery of $\mathbf{2 - Z n}(0.70 \mathrm{M}$ in DMF) was observed below $50{ }^{\circ} \mathrm{C}$ and gradual degradation occurred at $80{ }^{\circ} \mathrm{C}$. It was revealed that $50 \%$ decomposition of $\mathbf{2 - Z n}$ was observed after $4 \mathrm{~h}$ stirring, and almost all 2-Zn was decomposed after $12 \mathrm{~h}$ stirring (96\%). At $100{ }^{\circ} \mathrm{C}, \mathbf{2 - Z n}$ was almost completely decom- 
posed after being stirred for $2 \mathrm{~h}$, with a recovery yield of only $8 \%$. According to Beier's report [22,23], tetrafluoroethylmagnesium species fully decompose within $50 \mathrm{~min}$ at $-40{ }^{\circ} \mathrm{C}$; $\mathrm{CH}_{2}=\mathrm{CHCF}_{2} \mathrm{CF}_{2} \mathrm{ZnBr}$ (2-Zn) used in the present study was shown to be much more thermally stable than tetrafluoroethyllithium $[12,25]$ and -magnesium species [22,23].

The synthetic uses of $\mathbf{2 - Z n}$ as a promising tetrafluorinating agent were tested in several reactions. First, we demonstrated a typical $\mathrm{C}-\mathrm{C}$ bond formation reaction. Treating freshly prepared 2-Zn (ca. 0.70 M in DMF) with 5.0 equiv of iodobenzene (3a) in the presence of $10 \mathrm{~mol} \%$ of $\mathrm{CuI}$ in DMF at $50{ }^{\circ} \mathrm{C}$ for $24 \mathrm{~h}$ resulted in limited formation (11\% yield) of the cross-coupling product $4 \mathbf{a}$ (Table 2 , entry 1 ). The $\mathrm{Cu}(\mathrm{I})$-catalyzed cross-coupling reaction with $\mathbf{3 a}$ was proposed to take place via the following three key reaction steps [36]: (i) transmetallation from $\mathbf{2 - Z n}$ to the corresponding $\mathrm{Cu}$ (I) species, (ii) oxidative addition of a $\mathrm{C}_{\mathrm{Ar}}-\mathrm{I}$ bond to the $\mathrm{Cu}(\mathrm{I})$ atomic center to generate $\mathrm{Cu}(\mathrm{III})$ species, and (iii) reductive elimination of the product $\mathbf{4 a}$ along with the regeneration of the $\mathrm{Cu}(\mathrm{I})$ salt. When the initial transmetallation from $\mathbf{2}-\mathbf{Z n}$ to the reactive $\mathrm{Cu}(\mathrm{I})$ species proceeds much faster than the thermal decomposition of $\mathbf{2}-\mathbf{Z n}$, the yield of 4a should be improved. Indeed, in the cross-coupling reaction carried out at $80^{\circ} \mathrm{C}$ for $24 \mathrm{~h}$, an enhanced yield of $4 \mathbf{a}$ was observed (Table 2, entry 2), while the reaction in
THF did not give any trace of the product (Table 2, entry 3 ). Catalyst optimization (Table 2, entries 4-6) showed that $\mathrm{Cu}_{2} \mathrm{O}$ led to the highest product yield (46\%, Table 2, entry 6) [37]. After further exploring the reaction conditions (Table 2, entries $7-13$ ) including catalyst loading, equivalents of $\mathbf{3 a}$, additives, and reaction temperature, the best result (64\% NMR yield) was observed with 6.0 equiv of $\mathbf{3 a}$ in the presence of $30 \mathrm{~mol} \%$ of $\mathrm{Cu}_{2} \mathrm{O}$ in DMF at $100{ }^{\circ} \mathrm{C}$ for $24 \mathrm{~h}$ (Table 2, entry 12) [38].

Using the optimal conditions for the reaction in entry 12 , Table 2, various iodoarenes or -heteroarenes $(\mathbf{3 b}-\mathbf{r})$ could be converted into the corresponding $\mathrm{CF}_{2} \mathrm{CF}_{2}$-substituted aromatic compounds $\mathbf{4 b}-\mathbf{r}$ (Figure 3).

Aromatic iodides with an electron-donating group, such as OMe (3b) and $\mathrm{Me}(\mathbf{3 c})$, at the para position on the benzene ring were successfully coupled with $\mathbf{2 - Z n}$ under the optimized conditions to form $4 \mathbf{b}$ and $4 \mathbf{c}$ in $43 \%$ and $36 \%$ isolated yields, respectively. $p$-Chloro- (3d) or $p$-trifluoromethyl-substituted iodobenzene (3e) could also participate in the coupling reaction, leading to the corresponding products $\mathbf{4 d}$ and $\mathbf{4 e}$ in $53 \%$ and $75 \%$ NMR (49\% and $13 \%$ isolated) yields, respectively. Notably, iodoarenes with an ethoxycarbonyl (3f) or a nitro group (3g) at the para-position were successfully converted to the corresponding products $\mathbf{4 f}$ and $\mathbf{4 g}$ with good yields. Differences in the position

Table 2: Optimization of reaction conditions for $\mathrm{Cu}(\mathrm{I})$-catalyzed cross-coupling reaction of 2-Zn with iodobenzene (3a).

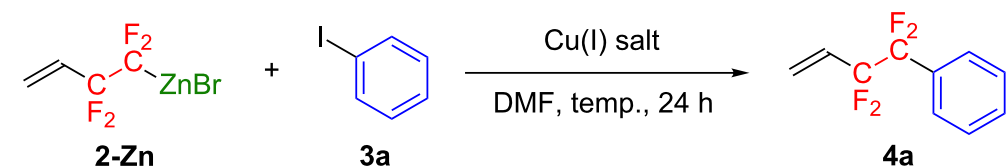

(ca. $0.70 \mathrm{M}$ in DMF)

\begin{tabular}{|c|c|c|c|c|}
\hline entrya & $\mathrm{Cu}(\mathrm{l})$ salt $(\mathrm{mol} \%)$ & 3a (equiv) & temp $\left({ }^{\circ} \mathrm{C}\right)^{b}$ & yield $^{c}(\%$ of $\mathbf{4 a})$ \\
\hline 1 & Cul (10) & 5.0 & 50 & 11 \\
\hline 2 & Cul (10) & 5.0 & 80 & 37 \\
\hline $3^{d}$ & Cul (10) & 5.0 & 80 & 0 \\
\hline 4 & CuBr (10) & 5.0 & 80 & 37 \\
\hline 5 & $\mathrm{CuCl}(10)$ & 5.0 & 80 & 34 \\
\hline 6 & $\mathrm{Cu}_{2} \mathrm{O}(10)$ & 5.0 & 80 & 46 \\
\hline 7 & $\mathrm{Cu}_{2} \mathrm{O}(30)$ & 5.0 & 80 & 53 \\
\hline 8 & $\mathrm{Cu}_{2} \mathrm{O}(50)$ & 5.0 & 80 & 54 \\
\hline $9^{e}$ & $\mathrm{Cu}_{2} \mathrm{O}(30)$ & 5.0 & 80 & 50 \\
\hline $10^{f}$ & $\mathrm{Cu}_{2} \mathrm{O}(30)$ & 5.0 & 80 & 35 \\
\hline 11 & $\mathrm{Cu}_{2} \mathrm{O}(30)$ & 6.0 & 80 & 59 \\
\hline 12 & $\mathrm{Cu}_{2} \mathrm{O}(30)$ & 6.0 & 100 & $64(29)^{g}$ \\
\hline 13 & $\mathrm{Cu}_{2} \mathrm{O}(30)$ & 6.0 & 120 & 57 \\
\hline
\end{tabular}

${ }^{a}$ Carried out using ca. $0.6 \mathrm{mmol}$ of $\mathbf{2 - Z n}$ in DMF solution (ca. $0.70 \mathrm{M}$ ). ${ }^{\mathrm{b}}$ Bath temperature. ${ }^{\mathrm{c}}$ Determined by ${ }^{19} \mathrm{~F}$ NMR. Values in parentheses are isolated yields. ${ }^{\mathrm{d}}$ The reaction was carried out using $\mathbf{2 - Z n}$ in THF instead of 2-Zn in DMF. ${ }^{~} N, N^{\prime}, N^{\prime}, N^{\prime}-$ Tetramethylethylenediamine (TMEDA) was used as an additive. ${ }^{f} 1,10$-Phenanthroline (phen) was used as an additive. ${ }^{9}$ The low isolated yield was due to the low boiling point and/or the high volatility of the product. 


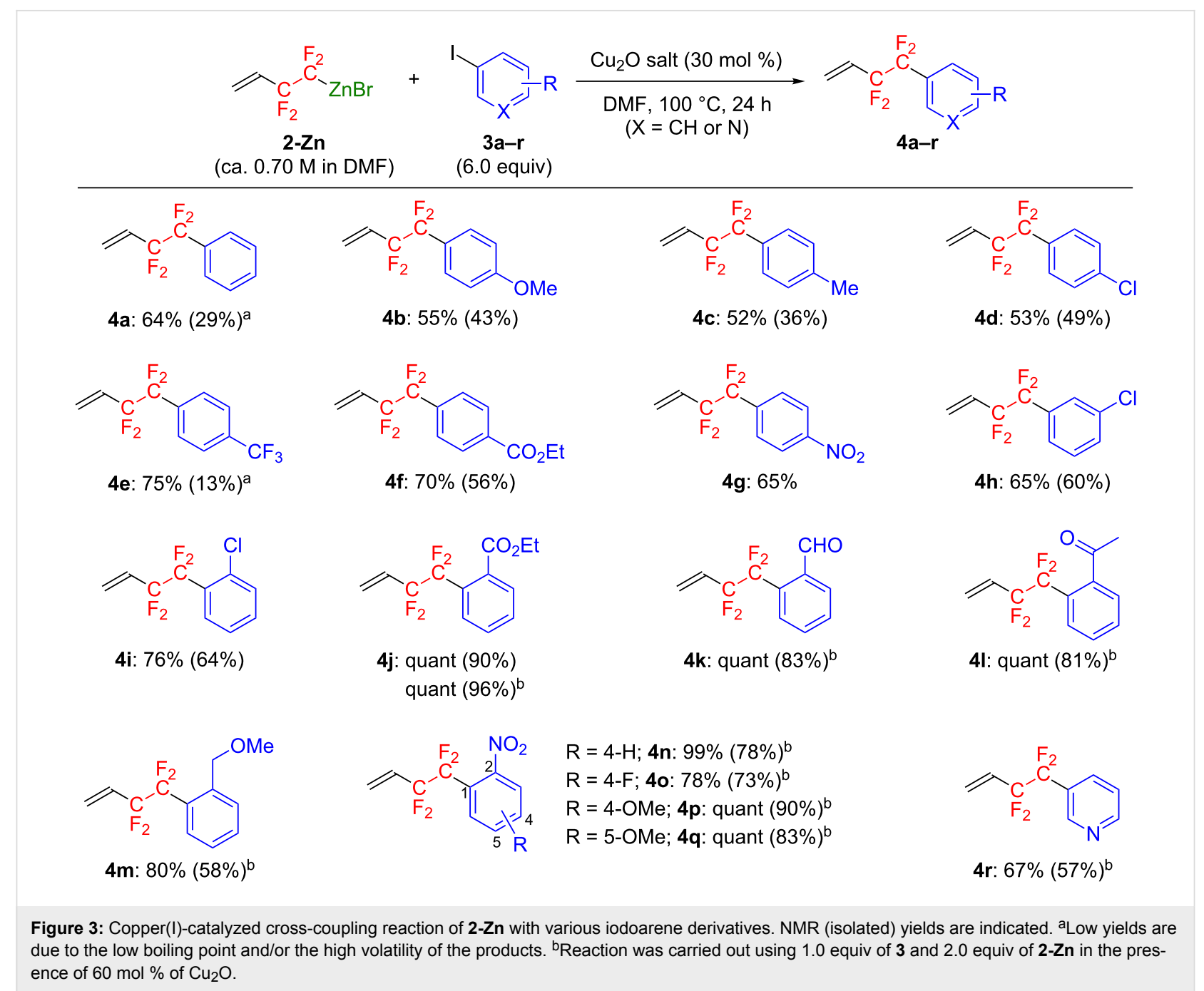

of the substituents on the benzene ring had no effect on the coupling reaction; $m$-chloro- (3h) and $o$-chloroiodobenzene (3i) were transformed into their corresponding products $4 \mathbf{h}$ and $\mathbf{4 i}$ in $60 \%$ and $64 \%$ yields, respectively. Interestingly, the reaction using ethyl $o$-iodobenzoate $(\mathbf{3} \mathbf{j})$ quite efficiently proceeded to give the coupling product $\mathbf{4} \mathbf{j}$ almost quantitatively. Comparing the result from the reaction with the para-substituted analog $\mathbf{3 f}$, the ester functionality at the ortho-position seems to significantly facilitate the formation of the coupling product. According to the previous reports by Jiang and co-workers [36], the oxygen atom in the ethoxycarbonyl group substituted at the ortho-position coordinates with the copper center to stabilize the $\mathrm{Cu}(\mathrm{III})$ intermediate, which facilitates the subsequent reductive elimination to form the desired coupling product. This acceleration effect of the ester functional group at the ortho-position led to a reduction in the chemical substances used. That is to say, the product $\mathbf{4} \mathbf{j}$ was obtained in a quantitative manner even when the reaction of 2-Zn was carried out with only a half equivalent of 3j. The same effect was also noted for iodoarenes having a labile functional group, such as formyl (3k), acetyl (3l), methoxymethyl $(\mathbf{3 m})$, or a nitro group $(\mathbf{3 n}-\mathbf{q})$ at the ortho-position, giving rise to the corresponding products $4 \mathbf{k}-\mathbf{q}$ with excellent efficiency. These results strongly suggest that $\mathbf{2 - Z n}$ can be successfully employed for the coupling reaction with an electrophile bearing a reactive functional group. Lastly, this synthetic protocol could be applied to prepare the $\mathrm{CF}_{2} \mathrm{CF}_{2}$-substituted heteroaromatic compound $\mathbf{4 r}$ from 3-iodopyridine (3r), demonstrating a promising pathway for constructing $\mathrm{CF}_{2} \mathrm{CF}_{2}$-containing heterocyclic compounds.

We also demonstrated the multigram preparation of $\mathrm{CF}_{2} \mathrm{CF}_{2-}$ containing arenes through the present cross-coupling reaction, as shown in Scheme 2. Thus, treatment of $1.38 \mathrm{~g}(5.00 \mathrm{mmol})$ of ethyl $o$-iodobenzoate $(\mathbf{3} \mathbf{j})$ with $10.1 \mathrm{mmol}$ of $\mathbf{2 - Z n}$ in the presence of $3 \mathrm{mmol}$ of $\mathrm{Cu}_{2} \mathrm{O}$ in DMF at $100{ }^{\circ} \mathrm{C}$ for $24 \mathrm{~h}$ gave $1.32 \mathrm{~g}(4.78 \mathrm{mmol})$ of the corresponding coupling product $\mathbf{4 j}$ (96\% yield). Similarly, the reaction of $\mathbf{2 - Z n}$ with $1.49 \mathrm{~g}$ of $o$-iodonitrobenzene $(\mathbf{3 n})$ afforded $1.25 \mathrm{~g}(5.02 \mathrm{mmol})$ of the 


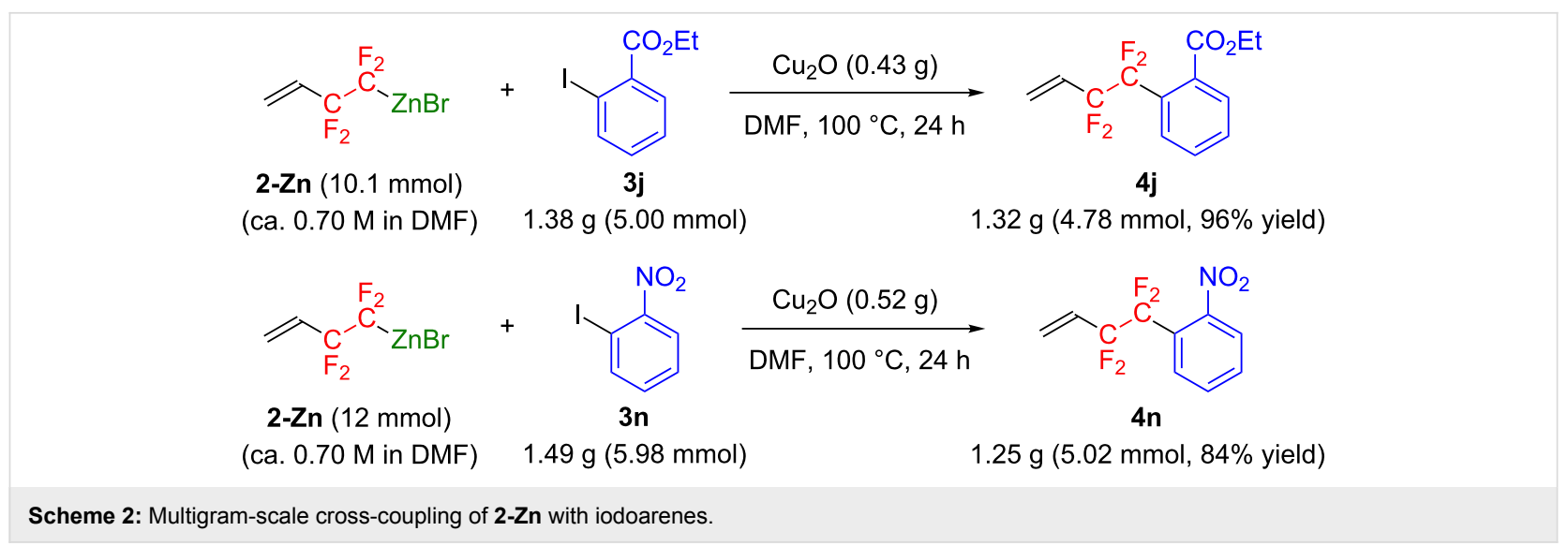

adduct $4 \mathbf{n}$ ( $84 \%$ yield). This achievement may lead to a significant contribution as a first scalable $\mathrm{CF}_{2} \mathrm{CF}_{2}$ fragment installation method.

To be further convinced of the importance of the present reaction, we carried out an additional transformation of the coupling adduct $4 \mathbf{n}$ to a $\mathrm{CF}_{2} \mathrm{CF}_{2}$-containing $\pi$-conjugates molecule, a fluorinated tolane derivative, applicable to promising functional materials, such as light-emitting and liquid-crystalline materials (Scheme 3) [39-44].

Thus, $\mathrm{CF}_{2} \mathrm{CF}_{2}$ group containing $\mathbf{4 n}$ with a nitro group at the ortho-position of the aromatic ring was effectively prepared from 2-Zn with the present protocol. 4n was smoothly converted to the corresponding aniline derivative $4 \mathrm{~s}$ in $87 \%$ isolated yield, after exposure to a reductive environment using $\mathrm{Fe}$ powder and $\mathrm{NH}_{4} \mathrm{Cl}$. Subsequent Sandmeyer reaction of $4 \mathbf{s}$ took place very nicely to afford the corresponding $\mathrm{CF}_{2} \mathrm{CF}_{2}$-substituted iodobenzene derivative $4 \mathrm{t}$ in $67 \%$ isolated yield. Then, $4 \mathrm{t}$ underwent $\operatorname{Pd}(0)$-catalyzed Sonogashira cross-coupling reaction with phenylacetylene, producing the corresponding tolane derivative $4 \mathbf{u}$ with a $\mathrm{CF}_{2} \mathrm{CF}_{2}$ fragment in good yield $(30 \%$ overall yield from $\mathbf{2 - Z n}$ ). Consequently, $\mathbf{2 - Z n}$ is found to be a powerful tetrafluoroethylenating agent for producing a broad range of organic molecules with a $\mathrm{CF}_{2} \mathrm{CF}_{2}$ unit.

Next, the $\mathrm{Cu}(\mathrm{I})$-catalyzed cross-coupling reaction of $\mathbf{2}-\mathbf{Z n}$ with benzoyl chloride (5a) as a coupling partner was investigated (Table 3).

Treating 2-Zn (ca. 0.70 M DMF solution) with 2.4 equiv of $\mathbf{5 a}$ in the presence of $\mathrm{CuI}(30 \mathrm{~mol} \%)$ in DMF at $100{ }^{\circ} \mathrm{C}$ for $20 \mathrm{~h}$ enabled the formation of the corresponding cross-coupling reaction product 6a in $67 \%$ yield (Table 3 , entry 1 ). Optimization of the $\mathrm{Cu}(\mathrm{I})$ catalyst for the benzoylation reaction (Table 3, entries 2-4) revealed that $\mathrm{Cu}_{2} \mathrm{O}$ was the most efficient for producing $6 \mathbf{a}$ ( $81 \%$ by NMR, Table 3 , entry 4 ). To further improve the reaction efficiency, three different additives (TMEDA, phen, and 2,2'-bipyridyl (bpy)) were tested. The first two additives were found to be ineffective for the present reaction (Table 3, entries 5 and 6), whereas bpy led to the quantitative formation of $\mathbf{6 a}$ (Table 3, entry 7). The facilitative effect of bpy as an additive made it possible to convert 5a to $\mathbf{6 a}$ even at ambient temperature (Table 3, entry 8 ). Additionally, to utilize the present reac-
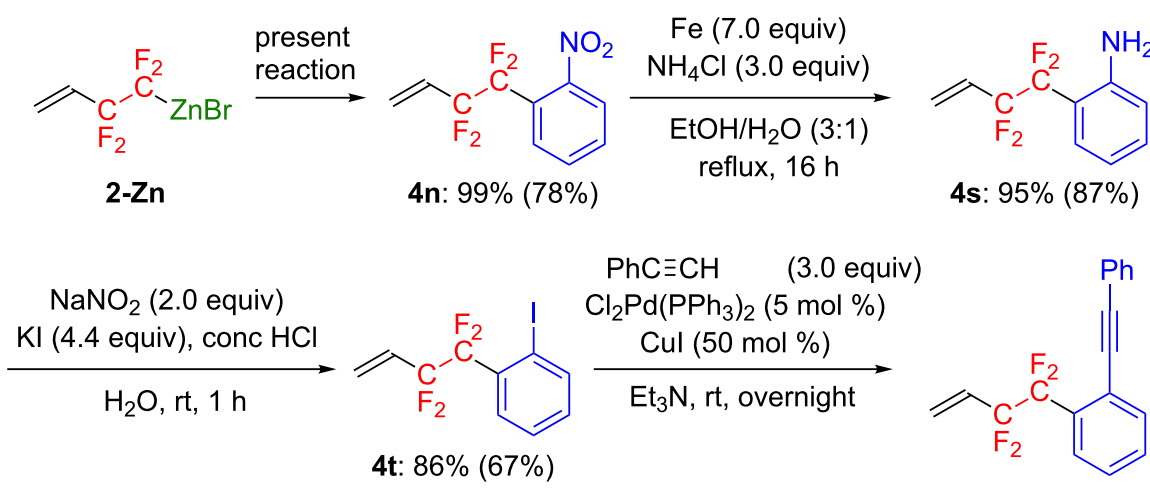

$\mathrm{PhC} \equiv \mathrm{CH} \quad$ (3.0 equiv) $\mathrm{Cl}_{2} \mathrm{Pd}\left(\mathrm{PPh}_{3}\right)_{2}(5 \mathrm{~mol} \%)$ Cul $(50 \mathrm{~mol} \%)$

$\mathrm{Et}_{3} \mathrm{~N}, \mathrm{rt}$, overnight

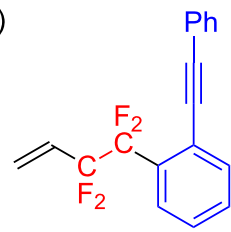

4u: $80 \%(69 \%)$ 
Table 3: Optimization of reaction conditions for $\mathrm{Cu}(\mathrm{I})$-catalyzed cross-coupling reaction of $\mathbf{2}-\mathbf{Z n}$ with benzoyl chloride (5a).

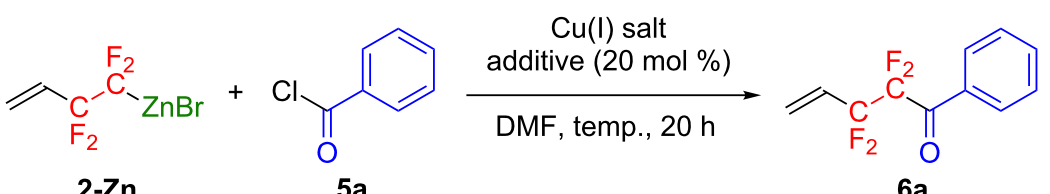

(ca. $0.70 \mathrm{M}$ in DMF)

\begin{tabular}{llllll}
\hline entry & $\mathrm{Cu}(\mathrm{I})$ salt $(\mathrm{mol} \%)$ & $\mathbf{5 a}$ (equiv) & additive & temp $^{\mathrm{a}}\left({ }^{\circ} \mathrm{C}\right)$ & yield $^{\mathrm{b}}(\%$ of $\mathbf{4 a})$ \\
\hline 1 & $\mathrm{Cul}(30)$ & 2.4 & - & 100 & 67 \\
2 & $\mathrm{CuBr}(30)$ & 2.4 & - & 100 & 51 \\
3 & $\mathrm{CuCN}(30)$ & 2.4 & - & 100 & 46 \\
4 & $\mathrm{Cu}_{2} \mathrm{O}(30)$ & 2.4 & - & 100 & 81 \\
5 & $\mathrm{Cu}_{2} \mathrm{O}(10)$ & 2.4 & TMEDA & 100 & $\mathrm{nd}^{\mathrm{c}}$ \\
6 & $\mathrm{Cu}_{2} \mathrm{O}(30)$ & 2.4 & phen & 100 & 69 \\
7 & $\mathrm{Cu}_{2} \mathrm{O}(50)$ & 2.4 & bpy & 100 & quant \\
8 & $\mathrm{Cu}_{2} \mathrm{O}(30)$ & $\mathbf{2 . 4}$ & bpy & rt & quant (92) \\
9 & $\mathrm{Cu}_{2} \mathrm{O}(30)$ & 2.0 & bpy & $\mathrm{rt}$ & 83 \\
\hline
\end{tabular}

aBath temperature. ${ }^{b}$ Determined by ${ }^{19} \mathrm{~F}$ NMR. Values in parentheses are isolated yield. ${ }^{\mathrm{C}}$ Not detected.

tion in an environmentally benign protocol, we conducted the reaction with a decreased amount of 5a. Unfortunately, this slightly lowered the yield of $\mathbf{6 a}$ (Table 3, entry 9).
With the optimized conditions (Table 3 , entry 8), various kinds of acid chlorides $\mathbf{5} \mathbf{b}-\mathbf{k}$ could be converted to the corresponding $\mathrm{CF}_{2} \mathrm{CF}_{2}$-substituted products $\mathbf{6 b}-\mathbf{k}$ (Figure 4).

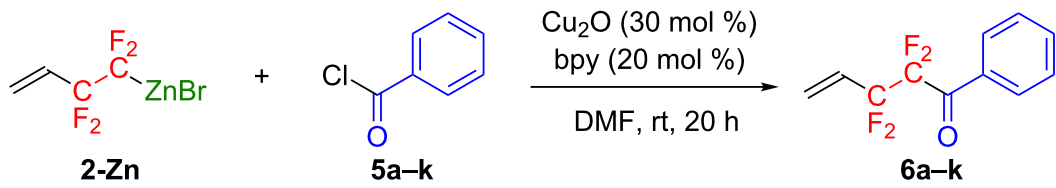

(ca. $0.70 \mathrm{M}$ in DMF) $\quad$ (2.4 equiv)<smiles>C=CC(F)C(=O)c1ccccc1</smiles>

6a: quant $(92 \%)$<smiles>C=CCC(F)C(=O)c1ccc(Br)cc1</smiles>

6e: $71 \%(50 \%)$<smiles>C=CCC(F)C(=O)c1cccs1</smiles>

6i: quant $(87 \%)$<smiles>C=CCC(F)C(=O)c1ccc(C)cc1</smiles>

6b: quant $(97 \%)$<smiles>C=CCC(F)C(=O)c1ccccc1C</smiles>

6c: quant $(83 \%)$<smiles>C=C[C-](F)C(=O)c1ccc(C(C)(C)C)cc1</smiles>

6d: quant (98\%)<smiles>C=CC(F)(F)C(=O)c1ccc(C(F)(F)F)cc1</smiles>

6f: quant $(86 \%)$<smiles>C=CC(F)(F)C(=O)c1ccc([N+](=O)[O-])cc1</smiles>

6g: $17 \%^{\text {a }}$ quant $(77 \%)^{a, b}$

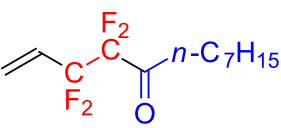

6k: quant $(84 \%)$ 
Benzoyl chloride derivatives with an electron-donating (5b-d) and an electron-withdrawing group $(\mathbf{5 e}, \mathbf{f})$ gave rise to the corresponding coupling products $\mathbf{6 b}-\mathbf{f}$ in $50-98 \%$ isolated yields. However, the reaction using nitro-substituted substrate $\mathbf{5 g}$ was quite slow under the same conditions. Slight modification of the reaction conditions, namely increasing the amount of $\mathbf{5 g}$ and raising the reaction temperature, significantly improved the yield of $\mathbf{6 g}$. Acid chlorides with a heteroaromatic moiety, e.g., $\mathbf{5 h}$ and $\mathbf{5 i}$, could also readily participate in the coupling reaction, leading to $\mathbf{6 h}$ and $\mathbf{6 i}$ in $83 \%$ and $87 \%$ isolated yields, respectively. Additionally, cinnamoyl chloride (5j) and $n$-octanoyl chloride (5k) were also suitable electrophiles to form the respective products $\mathbf{6 j}$ and $\mathbf{6 k}$ in high-to-excellent yields.

\section{Conclusion}

We developed a novel and practical tetrafluoroethylenating agent, viz. $\mathrm{CH}_{2}=\mathrm{CHCF}_{2} \mathrm{CF}_{2} \mathrm{ZnBr}(\mathbf{2}-\mathbf{Z n})$, which can be prepared in large-scale and stored for at least 1.5 years in the refrigerator without decomposition. $\mathbf{2 - Z n}$ could be successfully transformed into a broad range of $\mathrm{CF}_{2} \mathrm{CF}_{2}$-containing molecules with good-to-excellent efficiency. Considering that our previous study found that the vinyl moiety in the coupling product could be a useful molecular building block [14,45], 2-Zn presented here should be a suitable and valuable tetrafluoroethylenating agent for preparing various $\mathrm{CF}_{2} \mathrm{CF}_{2}$-containing molecules, thereby providing a powerful and practical synthetic tool in organofluorine chemistry.

\section{Supporting Information}

\section{Supporting Information File 1}

Experimental procedures, characterization data $\left({ }^{1} \mathrm{H},{ }^{13} \mathrm{C}\right.$, ${ }^{19} \mathrm{~F}$ NMR, IR and HRMS), copies of ${ }^{1} \mathrm{H},{ }^{13} \mathrm{C}$ and ${ }^{19} \mathrm{~F}$ NMR spectra.

[https://www.beilstein-journals.org/bjoc/content/ supplementary/1860-5397-14-213-S1.pdf]

\section{ORCID ${ }^{\circledR}$ iDs}

Shigeyuki Yamada - https://orcid.org/0000-0002-6379-0447 Tsutomu Konno - https://orcid.org/0000-0002-5146-9840

\section{References}

1. Kaplan, P. T.; Vicic, D. A. Org. Lett. 2016, 18, 884-886. doi:10.1021/acs.orglett.6b00032

2. Irie, M. Pure Appl. Chem. 2015, 87, 617-626. doi:10.1515/pac-2015-0208

3. Biffinger, J. C.; Kim, H. W.; DiMagno, S. G. ChemBioChem 2004, 5, 622-627. doi:10.1002/cbic.200300910

4. Kim, H. W.; Rossi, P.; Shoemaker, R. K.; DiMagno, S. G. J. Am. Chem. Soc. 1998, 120, 9082-9083. doi:10.1021/ja9803714
5. O'Hagan, D. Chem. Soc. Rev. 2008, 37, 308-319. doi:10.1039/b711844a

6. Müller, K.; Faeh, C.; Diederich, F. Science 2007, 317, 1881-1886. doi:10.1126/science. 1131943

7. van Straaten, K. E.; Kuttiyatveetil, J. R. A.; Sevrain, C. M.; Villaume, S. A.; Jiménez-Barbero, J.; Linclau, B.; Vincent, S. P.; Sanders, D. A. R. J. Am. Chem. Soc. 2015, 137, 1230-1244. doi:10.1021/ja511204p

8. Timofte, R. S.; Linclau, B. Org. Lett. 2008, 10, 3673-3676. doi:10.1021/ol801272e

9. Boydell, A. J.; Vinader, V.; Linclau, B. Angew. Chem., Int. Ed. 2004, 43, 5677-5679. doi:10.1002/anie.200460746

10. Bonnac, L.; Lee, S. E.; Giuffredi, G. T.; Elphick, L. M.; Anderson, A. A.; Child, E. S.; Mann, D. J.; Gouverneur, V. Org. Biomol. Chem. 2010, 8, 1445-1454. doi:10.1039/b922442d

11. Kirsch, P.; Bremer, M.; Huber, F.; Lannert, H.; Ruhl, A.; Lieb, M.; Wallmichrath, T. J. Am. Chem. Soc. 2001, 123, 5414-5417. doi:10.1021/ja010024l

12. Konno, T.; Hoshino, T.; Kida, T.; Takano, S.; Ishihara, T. J. Fluorine Chem. 2013, 152, 106-113. doi:10.1016/j.jfluchem.2013.02.013

13. Kumon, T.; Hashishita, S.; Kida, T.; Yamada, S.; Ishihara, T.; Konno, T. Beilstein J. Org. Chem. 2018, 14, 148-154. doi:10.3762/bjoc.14.10

14. Yamashika, K.; Morishitabara, S.; Yamada, S.; Kubota, T.; Konno, T. J. Fluorine Chem. 2018, 207, 24-37. doi:10.1016/j.jfluchem.2017.12.013

15. Yamada, S.; Tamamoto, K.; Kida, T.; Asai, T.; Ishihara, T.; Konno, T. Org. Biomol. Chem. 2017, 15, 9442-9454. doi:10.1039/C7OB02399E

16. Yamada, S.; Hashishita, S.; Konishi, H.; Nishi, Y.; Kubota, T.; Asai, T.; Ishihara, T.; Konno, T. J. Fluorine Chem. 2017, 200, 47-58. doi:10.1016/j.jluchem.2017.05.013

17. Yamada, S.; Hashishita, S.; Asai, T.; Ishihara, T.; Konno, T. Org. Biomol. Chem. 2017, 15, 1495-1509. doi:10.1039/C6OB02431A

18. Ohashi, M.; Adachi, T.; Ishida, N.; Kikushima, K.; Ogoshi, S. Angew. Chem., Int. Ed. 2017, 56, 11911-11915. doi:10.1002/anie.201703923

19. Kikushima, K.; Sakaguchi, H.; Saijo, H.; Ohashi, M.; Ogoshi, S. Chem. Lett. 2015, 44, 1019-1021. doi:10.1246/cl.150322

20. Saijo, H.; Ohashi, M.; Ogoshi, S. J. Am. Chem. Soc. 2014, 136, 15158-15161. doi:10.1021/ja5093776

21. O'Duill, M.; Dubost, E.; Pfeifer, L.; Gouverneur, V. Org. Lett. 2015, 17, 3466-3469. doi:10.1021/acs.orglett.5b01510

22. Voltrová, S.; Muselli, M.; Filgas, J.; Matoušek, V.; Klepetářová, B.; Beier, P. Org. Biomol. Chem. 2017, 15, 4962-4965. doi:10.1039/c7ob01151b

23. Budinská, A.; Václavík, J.; Matoušek, V.; Beier, P. Org. Lett. 2016, 18, 5844-5847. doi:10.1021/acs.orglett.6b02890

24. Watanabe, Y.; Konno, T. J. Fluorine Chem. 2015, 174, 102-107. doi:10.1016/j.jfluchem.2014.12.008

25. Konno, T.; Takano, S.; Takahashi, Y.; Konishi, H.; Tanaka, Y.; Ishihara, T. Synthesis 2011, 33-44. doi:10.1055/s-0030-1258330

26. Dmowski, W. J. Fluorine Chem. 2012, 142, 6-13. doi:10.1016/j.jluchem.2012.06.018

27. Chambers, R. D. Chapter 10. In Fluorine in Organic Chemistry; Chambers, R. D., Ed.; Blackwell Publishing Ltd.: Hoboken, NJ, U.S.A., 2004. doi:10.1002/9781444305371

28. Uno, H.; Suzukib, H. Synlett 1993, 91-96. doi:10.1055/s-1993-22361 
29. Knochel, P.; Leuser, H.; Gong, L.-Z.; Perrone, S. Chapter 7. In Handbook of Functionalized Organometallics, Applications in Synthesis; Knochel, P., Ed.; Wiley-VCH Verlag GmbH\&Co. KGaA: Weinheim, Germany, 2005.

30. Kato, H.; Hirano, K.; Kurauchi, D.; Toriumi, N.; Uchiyama, M. Chem. - Eur. J. 2015, 21, 3895-3900. doi:10.1002/chem.201406292

31. Aikawa, K.; Nakamura, Y.; Yokota, Y.; Toya, W.; Mikami, K. Chem. - Eur. J. 2015, 21, 96-100. doi:10.1002/chem.201405677

32. Popov, I.; Lindeman, S.; Daugulis, O. J. Am. Chem. Soc. 2011, 133, 9286-9289. doi:10.1021/ja2041942

33. Burton, D. J.; Jairaj, V. J. Fluorine Chem. 2004, 125, 673-680. doi:10.1016/j.jfluchem.2003.11.010

34. Jiang, B.; Xu, Y. J. Org. Chem. 1991, 56, 7336-7340. doi:10.1021/jo00026a028

35. After storage in the refrigerator for 1.5 years, the $\mathbf{2}-\mathbf{Z n}$ solution was found to have the same concentration as the freshly prepared one, as measured by quantitative titration. Furthermore, the one and a half-year-old reagent was also quantitatively coupled with ethyl 2-iodobenzoate $(\mathbf{3 j})$ to give the corresponding $4 \mathbf{j}$. The details are described in Scheme $\mathrm{S} 1$ in Supporting Information File 1.

36. Jiang, H.; Lu, W.; Yang, K.; Ma, G.; Xu, M.; Li, J.; Yao, J.; Wan, W.; Deng, H.; Wu, S.; Zhu, S.; Hao, J. Chem. - Eur. J. 2014, 20 , 10084-10092. doi:10.1002/chem.201402205

37. Li, J.-H.; Tang, B.-X.; Tao, L.-M.; Xie, Y.-X.; Liang, Y.; Zhang, M.-B. J. Org. Chem. 2006, 71, 7488-7490. doi:10.1021/jo061220j

38. We also carried out the reaction of $2-\mathrm{Zn}$ with $3 \mathrm{a}$ under the influence of $100 \mathrm{~mol} \%$ of $\mathrm{Cu}_{2} \mathrm{O}$ in DMF at $100{ }^{\circ} \mathrm{C}$ for $1 \mathrm{~h}$. As a result, it was found that $4 \mathrm{a}$ could be obtained in $58 \%$ yield. This result indicates that this catalytic cycle proceeds quickly.

39. Peng, Z.; Wang, Q.; Liu, Y.; Mu, Q.; Cao, Z.; Xu, H.; Zhang, P.; Yang, C.; Yao, L.; Xuan, L.; Zhang, Z. Liq. Cryst. 2016, 43, 276-284. doi:10.1080/02678292.2015.1105311

40. Li, B.; He, W.; Wang, L.; Xiao, X.; Yang, H. Soft Matter 2013, 9 , 1172-1177. doi:10.1039/c2sm26807h

41. Hird, M.; Toyne, K. J.; Goodby, J. W.; Gray, G. W.; Minter, V.; Tuffin, R. P.; McDonnell, D. G. J. Mater. Chem. 2004, 14, 1731-1743. doi:10.1039/b400630e

42. Yamada, S.; Morita, M.; Konno, T. J. Fluorine Chem. 2017, 202, 54-64. doi:10.1016/j.jfluchem.2017.09.003

43. Yamada, S.; Miyano, K.; Konno, T.; Agou, T.; Kubota, T.; Hosokai, T. Org. Biomol. Chem. 2017, 15, 5949-5958. doi:10.1039/C7OB01369H

44. Reimann, S.; Wittler, K.; Schmode, S.; Sharif, M.; Fahrenwaldt, T.; Ludwig, R.; Spannenberg, A.; Langer, P. Eur. J. Org. Chem. 2013, 8115-8134. doi:10.1002/ejoc.201300607

45. Sakaguchi, Y.; Yamada, S.; Konno, T.; Agou, T.; Kubota, T. J. Org. Chem. 2017, 82, 1618-1631. doi:10.1021/acs.joc.6b02793

\section{License and Terms}

This is an Open Access article under the terms of the Creative Commons Attribution License (http://creativecommons.org/licenses/by/4.0). Please note that the reuse, redistribution and reproduction in particular requires that the authors and source are credited.

The license is subject to the Beilstein Journal of Organic Chemistry terms and conditions:

(https://www.beilstein-journals.org/bjoc)

The definitive version of this article is the electronic one which can be found at:

doi:10.3762/bjoc. 14.213 